\title{
Evidence of the metal-insulator transition in ultrathin unstrained $\mathrm{V}_{2} \mathrm{O}_{3}$ thin films
}

\author{
L. Dillemans, ${ }^{\text {a) }}$ T. Smets, R. R. Lieten, M. Menghini, C.-Y. Su, and J.-P. Locquet \\ Departement Natuurkunde en Sterrenkunde, Katholieke Universiteit Leuven, Celestijnenlaan 200D, \\ 3001 Heverlee, Belgium
}

(Received 13 November 2013; accepted 3 February 2014; published online 18 February 2014)

\begin{abstract}
We report the strain state and transport properties of $\mathrm{V}_{2} \mathrm{O}_{3}$ layers and $\mathrm{V}_{2} \mathrm{O}_{3} / \mathrm{Cr}_{2} \mathrm{O}_{3}$ bilayers deposited by molecular beam epitaxy on (0001) $-\mathrm{Al}_{2} \mathrm{O}_{3}$. By changing the layer on top of which $\mathrm{V}_{2} \mathrm{O}_{3}$ is grown, we change the lattice parameters of ultrathin $\mathrm{V}_{2} \mathrm{O}_{3}$ films significantly. We find that the metal-insulator transition is strongly attenuated in ultrathin $\mathrm{V}_{2} \mathrm{O}_{3}$ layers grown coherently on $\mathrm{Al}_{2} \mathrm{O}_{3}$. This is in contrast with ultrathin $\mathrm{V}_{2} \mathrm{O}_{3}$ layers grown on $\mathrm{Cr}_{2} \mathrm{O}_{3}$ buffer layers, where the metal-insulator transition is preserved. Our results provide evidence that the existence of the transition in ultrathin films is closely linked with the lattice deformation. (C) 2014 AIP Publishing LLC. [http://dx.doi.org/10.1063/1.4866004]
\end{abstract}

Vanadium sesquioxide $\left(\mathrm{V}_{2} \mathrm{O}_{3}\right)$ has been the focus of intense research by both theorists and experimentalists since the discovery of a Metal-Insulator transition (MIT) in this material. ${ }^{1}$ A phase diagram for bulk $\mathrm{V}_{2} \mathrm{O}_{3}$ was established by McWhan et al. ${ }^{2}$ At ambient conditions, stoichiometric $\mathrm{V}_{2} \mathrm{O}_{3}$ is a paramagnetic metal (PM) with a rhombohedral structure that is isostructural with corundum $\mathrm{Al}_{2} \mathrm{O}_{3}$ (spacegroup $\mathrm{R}-3 \mathrm{c}$ ). Upon cooling below $150-160 \mathrm{~K}, \mathrm{~V}_{2} \mathrm{O}_{3}$ undergoes a MIT with an increase in resistivity of over 7 orders of magnitude to an antiferromagnetic insulating state (AFI), accompanied by a monoclinic distortion. The state of the material can be influenced by stoichiometry, doping or hydrostatic pressure. These parameters have an "equivalent" effect: A "negative" pressure ${ }^{3}$ or doping with a small percentage of $\mathrm{Cr}$ stabilizes a paramagnetic insulating phase that is isostructural with respect to the PM phase. On the other hand, application of hydrostatic pressure, a small percentage of $\mathrm{Ti}$ doping or an oxygen excess ${ }^{4}$ results in a gradual decrease of the PM-AFI transition temperature down to $0 \mathrm{~K}$, stabilizing the PM phase at all temperatures.

Thin films of materials that exhibit a MIT offer interesting prospects for integration in device structures, including piezoelectronic ${ }^{5}$ and field-effect transistors. ${ }^{6}$ The performance of these devices benefits in many cases from the active material being (ultra-)thin since this allows increased switching speed. Additionally, a more pronounced switching effect is expected when the active layer has a thickness comparable with the screening length $(\sim 1 \mathrm{~nm}) . \mathrm{V}_{2} \mathrm{O}_{3}$, considered to be a prototypical Mott-Hubbard system, can be used as a model system to study the MIT characteristics upon scaling. In particular, it remains an open question whether or not a pronounced MIT can be achieved in $\mathrm{V}_{2} \mathrm{O}_{3}$ ultrathin layers. The proximity of surfaces and interfaces can possibly have a dramatic effect on the transport properties. In particular, Borghi et $a .^{7}$ predict a surface dead layer where the quasi-particle weight at the Fermi level is reduced with respect to the bulk value for a Mott material near an interface. Evidence for the existence of such a layer has indeed been found in photoemission spectroscopy measurements of bulk $\mathrm{V}_{2} \mathrm{O}_{3} \cdot{ }^{8,9}$ Based on

a)leander.dillemans@gmail.com assumptions for the value of the photoelectron mean free path and the profile of the quasi-particle weight, Rodolakis et al. ${ }^{9}$ made a rough estimate of $4 \mathrm{~nm}$ for the thickness of this layer. Furthermore, a number of authors report the absence or a significant attenuation of the MIT in ultrathin layers. ${ }^{10-12}$

In this work, we investigate the influence of a $\mathrm{Cr}_{2} \mathrm{O}_{3}$ buffer layer and the $\mathrm{V}_{2} \mathrm{O}_{3}$ thickness on the transport properties. We demonstrate a MIT in ultrathin $\mathrm{V}_{2} \mathrm{O}_{3}$ layers down to $3.5 \pm 1 \mathrm{~nm}$ by inserting high quality and (almost) relaxed $\mathrm{Cr}_{2} \mathrm{O}_{3}$ buffer layers between the $\mathrm{V}_{2} \mathrm{O}_{3}$ and the (0001) $-\mathrm{Al}_{2} \mathrm{O}_{3}$ substrate.

Layers of $\mathrm{V}_{2} \mathrm{O}_{3}$ and $\mathrm{Cr}_{2} \mathrm{O}_{3}$ were deposited by means of oxygen assisted molecular beam epitaxy in a vacuum chamber (Riber) with a base pressure of $10^{-9}$ millibars. Substrates of (0001) $-\mathrm{Al}_{2} \mathrm{O}_{3}\left(1 \times 1 \mathrm{~cm}^{2}\right)$ were used without prior cleaning or flash annealing at elevated temperatures. The substrates were heated slowly to the growth temperature, measured by a thermo-couple. Cr was evaporated from a Knudsen cell and V was evaporated from an electron gun (MBE Komponenten). A deposition rate of $0.1 \AA / s$ was used for both metals. In the case of the $\mathrm{V}_{2} \mathrm{O}_{3} / \mathrm{Cr}_{2} \mathrm{O}_{3}$ bilayers, $\mathrm{V}_{2} \mathrm{O}_{3}$ was deposited in-situ right after $\mathrm{Cr}_{2} \mathrm{O}_{3}$. An oxygen partial pressure of $6 \times 10^{-6}$ $\left(2 \times 10^{-6}\right)$ Torr and growth temperature of $700(720)^{\circ} \mathrm{C}$ was used for deposition of the $\mathrm{V}_{2} \mathrm{O}_{3}\left(\mathrm{Cr}_{2} \mathrm{O}_{3}\right)$ layers. After deposition, the samples were characterized by means of high resolution X-ray diffraction (XRD), X-ray reflectivity (XRR), and X-ray reciprocal space mapping (RSM) using a Panalytical X'pert Pro diffractometer. Temperature dependent transport properties were assessed by performing resistivity measurements in the Van der Pauw (VDP) and collinear configurations, using $\mathrm{Au} / \mathrm{Cr}$ contacts and an Oxford Optistat CF2-V cryostat with a sweep rate of $1.5 \mathrm{~K}$ per minute.

First, we investigated $\mathrm{V}_{2} \mathrm{O}_{3}$ layers deposited directly on (0001) $-\mathrm{Al}_{2} \mathrm{O}_{3}$. An XRD $\theta / 2 \theta$ scan of the (0006) reflection of a $57 \mathrm{~nm} \mathrm{~V}_{2} \mathrm{O}_{3}$ layer grown on $\mathrm{Al}_{2} \mathrm{O}_{3}$ is shown in Fig. 1. High quality epitaxial deposition with a smooth surface and interface is evident from the appearance of Pendelössung fringes. Moreover, identical thickness values are extracted from fittings of the XRR and XRD data. 


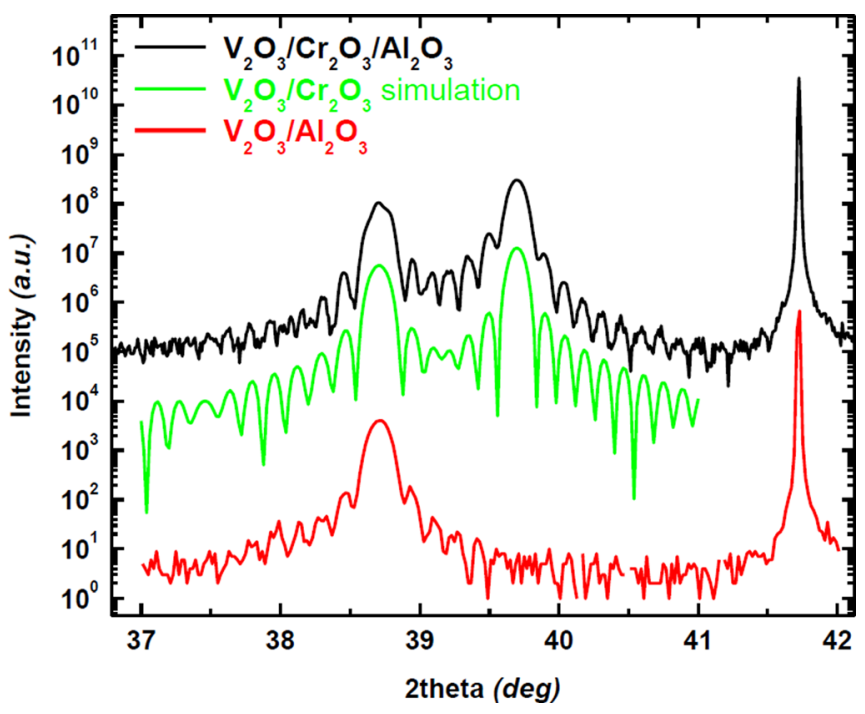

FIG. 1. XRD $\theta / 2 \theta$ scans for a 57 and $56 \mathrm{~nm} \mathrm{~V}_{2} \mathrm{O}_{3}$ layer grown on $\mathrm{Al}_{2} \mathrm{O}_{3}$ (red) and $\mathrm{Cr}_{2} \mathrm{O}_{3} / \mathrm{Al}_{2} \mathrm{O}_{3}$ (black), respectively. The green curve is a simulation of the latter.

RSMs around the $\left(\begin{array}{lll}1 & 0 & \overline{1} 10\end{array}\right)$ reflections of $\mathrm{V}_{2} \mathrm{O}_{3}$ and $\mathrm{Al}_{2} \mathrm{O}_{3}$ are shown in Fig. 2 for layers with different thicknesses. The lattice parameters extracted from the peak maximum for layers with thicknesses between 73 and $17 \mathrm{~nm}$ (not all shown) correspond well with the bulk values of $\mathrm{a}=4.954 \AA$ and $\mathrm{c}=14.008 \AA$, apart from a small tensile (compressive) in-plane (out-of-plane) strain scattered between $0.2(-0.44) \%$ and 0.34 $(-0.49) \%$, which is most likely thermal in nature. ${ }^{13}$ These layers exhibit elliptical peak shapes that are broadened as a result of tilt and finite in- and out-of-plane coherence lengths. In addition to a relaxed feature, the film with $17 \mathrm{~nm}$ thickness

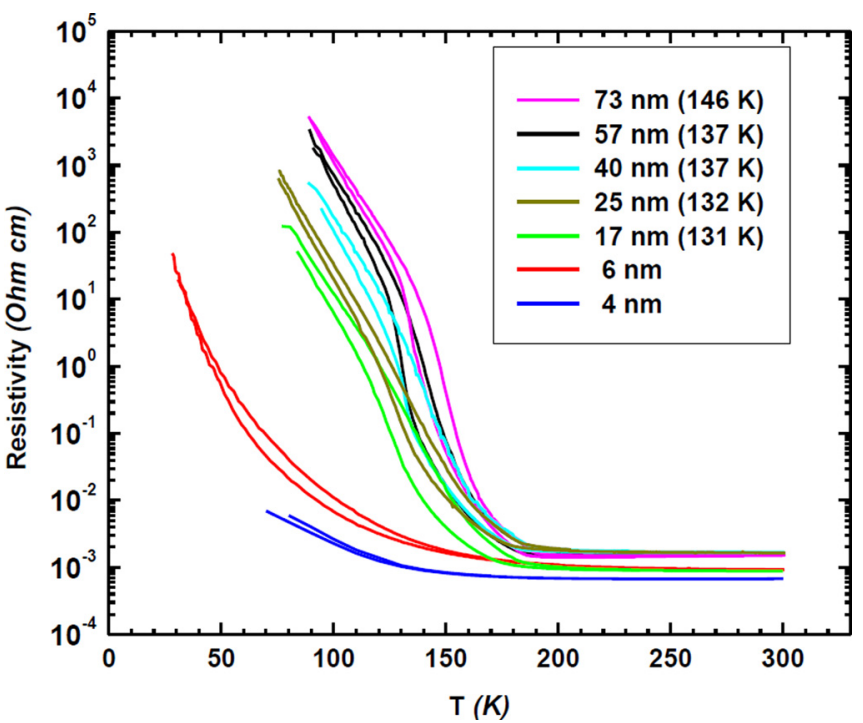

FIG. 3. Resistivity of $\mathrm{V}_{2} \mathrm{O}_{3}$ layers with different thickness deposited directly on (0001) $-\mathrm{Al}_{2} \mathrm{O}_{3}$. $\mathrm{T}_{\text {MIT }}$ values are given in the legend.

exhibits a faint thin stripe located at the same a-axis position as the substrate and smeared out along the c-axis direction. This is indicative of a coherent component present in the layer, lattice matched with the substrate (same $Q_{\mathrm{x}}$ ). The relative intensity of the coherent feature increases systematically as the thickness is decreased to 6 and $4 \mathrm{~nm}$. In the $4 \mathrm{~nm}$ layer, the relaxed feature is barely visible and we can conclude that the layer is almost fully coherently strained.

Resistivity hysteresis curves as a function of temperature are shown in Fig. 3 for $\mathrm{V}_{2} \mathrm{O}_{3}$ layers with different thickness grown directly on $\mathrm{Al}_{2} \mathrm{O}_{3}$. The transition temperature $\left(\mathrm{T}_{\mathrm{MIT}}\right)$ is determined from the first derivative of either the

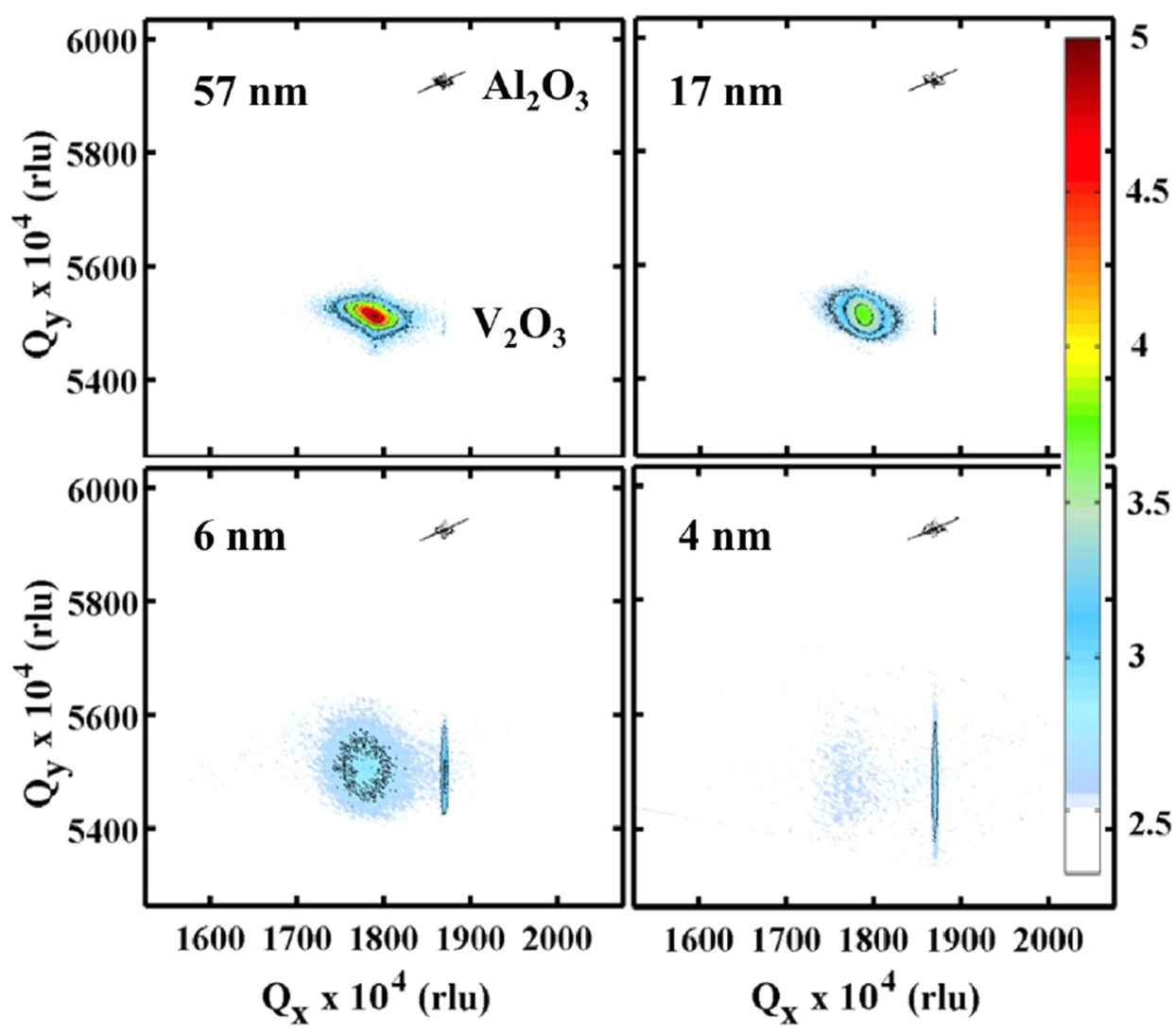

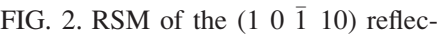
tion of $\mathrm{V}_{2} \mathrm{O}_{3}$ layers deposited directly on (0001) $-\mathrm{Al}_{2} \mathrm{O}_{3} \cdot \mathrm{Q}_{\mathrm{x}}$ and $\mathrm{Q}_{\mathrm{y}}$ are the components of the scattering vector along in- and out-of-plane directions, respectively. The intensity scale is logarithmic. 
heating or cooling curve (whichever is most symmetric) and corrected for the hysteresis. The thickest layer of $73 \mathrm{~nm}$ exhibits a MIT of four decades in resistivity at $146 \mathrm{~K}$. The resistivity at room temperature is $1.6 \times 10^{-3} \Omega \mathrm{cm}$, slightly higher than the bulk value of about $5 \times 10^{-4} \Omega \mathrm{cm} .{ }^{14}$ As the thickness is decreased to $17 \mathrm{~nm}, \mathrm{~T}_{\mathrm{MIT}}$ decreases from $146 \mathrm{~K}$ to $131 \mathrm{~K}$ and the resistivity ratio (RR), defined as the ratio of resistivity values at $300 \mathrm{~K}$ and $120 \mathrm{~K}$, decreases from $7.5 \times 10^{4}$ to $7 \times 10^{2}$.

The layers with thicknesses of 6 and $4 \mathrm{~nm}$ exhibit a qualitatively different behavior from the thicker layers. There is no sharp transition and the slope of both cooling and heating curves increases (almost) monotonically with decreasing temperature. There is however still hysteresis present between cooling and heating curves. This suggests that the transition is attenuated significantly in layers that are coherently strained on $\mathrm{Al}_{2} \mathrm{O}_{3}$. The $4 \mathrm{~nm}$ thick sample exhibited a significant asymmetry between measurements along different directions. Whether this is intrinsic, due to sample inhomogeneity or anisotropic crystal sizes needs to be further investigated by conductivity measurements at the nanoscale.

In order to study the possibility of an intrinsic critical thickness for the PM-AFI transition to occur, it is necessary to synthesize layers that have a limited interaction with the substrate and bulk-like structural characteristics. For instance, dramatic changes in the transport properties can be directly linked to the epitaxial strain state in ultrathin films of some transition metal oxides. ${ }^{15}$ Most of the $\mathrm{V}_{2} \mathrm{O}_{3}$ thin film work reported in the literature involves the epitaxial deposition of $\mathrm{V}_{2} \mathrm{O}_{3}$ on substrates that have a rather large misfit with $\mathrm{V}_{2} \mathrm{O}_{3} \cdot{ }^{3,10-13,16-20}$ In particular, (0001)-oriented $\mathrm{Al}_{2} \mathrm{O}_{3}$ with hexagonal unit cell spacings of $\mathrm{a}=4.754 \AA$ and $\mathrm{c}=12.975 \AA$ is often used as a substrate. Bulk $\mathrm{V}_{2} \mathrm{O}_{3}$ has lattice spacings of $\mathrm{a}=4.954 \AA$ and $\mathrm{c}=14.008 \AA$. The misfit between $\mathrm{V}_{2} \mathrm{O}_{3}$ and $\mathrm{Al}_{2} \mathrm{O}_{3}$, defined as $\left(a_{V 203}-a_{A / 203}\right) / a_{A / 203}$ for deposition on a (0001)-oriented substrate is therefore $4.2 \%$. As a result, below the critical thickness for relaxation via introduction of misfit dislocations, the layer is coherently strained with lattice parameters differing significantly from the bulk values, as can be seen from Fig. 2. Apart from being directly affected by the strain state, the MIT could also be attenuated in coherently strained layers as a result of the strong interaction with the substrate, which could hamper the structural transition to the AFI state. Indeed, it has been shown that enhanced coupling with the (0001) $-\mathrm{Al}_{2} \mathrm{O}_{3}$ substrate leads to a significant broadening of the $\mathrm{V}_{2} \mathrm{O}_{3}$ (0006) reflection in XRD and the suppression of the MIT. ${ }^{16}$

In order to lower the substrate influence on thin layers, we have used $\mathrm{Cr}_{2} \mathrm{O}_{3}$ buffer layers. The misfit between bulk (0001) $-\mathrm{V}_{2} \mathrm{O}_{3}$ and $(0001)-\mathrm{Cr}_{2} \mathrm{O}_{3}(\mathrm{a}=4.959 \AA$ and $\mathrm{c}=13.594 \AA)$ is only $-0.1 \%$. We expect therefore a significantly smaller strain for ultrathin $\mathrm{V}_{2} \mathrm{O}_{3}$ layers deposited on $\mathrm{Cr}_{2} \mathrm{O}_{3}$. It has already been shown that a buffer layer of $\mathrm{Cr}_{2} \mathrm{O}_{3}$ significantly decreases the transition width in e-beam evaporated films of 20-450 nm thickness. ${ }^{21}$

RSMs for layers of $\mathrm{V}_{2} \mathrm{O}_{3}$ grown on a $\mathrm{Cr}_{2} \mathrm{O}_{3}$ buffer layer are shown in Fig. 4. The thickness of the $\mathrm{Cr}_{2} \mathrm{O}_{3}$ layers, determined from fits of the XRD data (Fig. 1), is found to vary between 67.5 and $68.5 \mathrm{~nm}$ from sample to sample. The thickness of the $\mathrm{V}_{2} \mathrm{O}_{3}$ layers is determined from XRR. Apart from a faint coherent feature, the $\mathrm{Cr}_{2} \mathrm{O}_{3}$ is nearly relaxed towards its bulk values, exhibiting a small compressive in-plane strain. Compressive strain is indeed expected from the misfit with the $\mathrm{Al}_{2} \mathrm{O}_{3}$ substrate. The 56 and $14 \mathrm{~nm} \mathrm{~V}_{2} \mathrm{O}_{3}$ layers

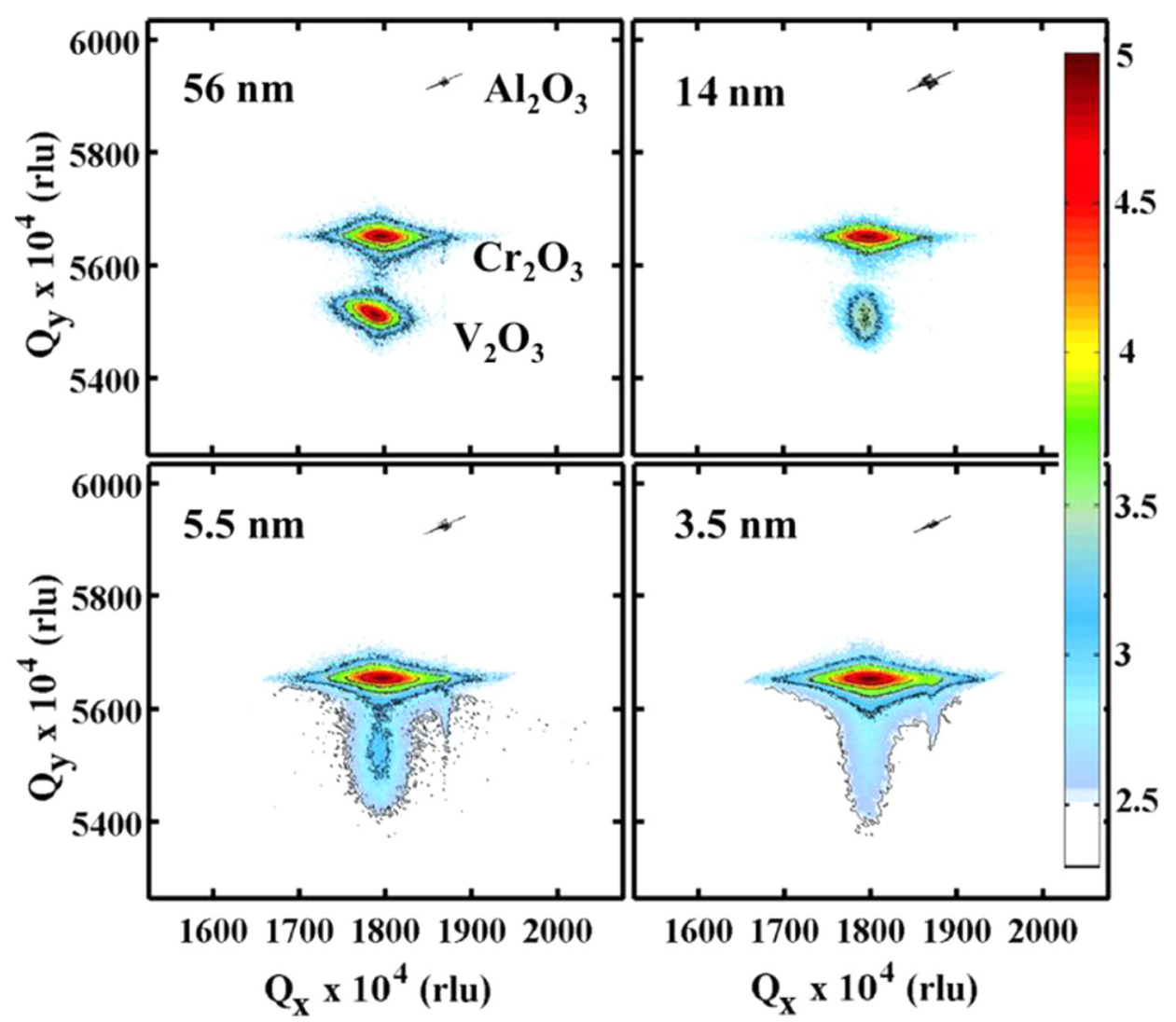

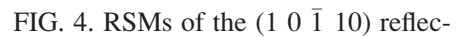
tion of $\mathrm{V}_{2} \mathrm{O}_{3}$ deposited on $\mathrm{Cr}_{2} \mathrm{O}_{3}$ / (0001) $-\mathrm{Al}_{2} \mathrm{O}_{3}$. The intensity scale is logarithmic. 
exhibit an in-plane (out-of-plane) strain state of $0.21 \%$ $(-0.47 \%)$ and $0.00 \%(-0.39 \%)$, which is possibly thermal in nature. It is clear from the absence of a coherent component (with respect to $\mathrm{Al}_{2} \mathrm{O}_{3}$ ) for $\mathrm{V}_{2} \mathrm{O}_{3}$ as is observed in Fig. 2 that the buffer layer effectively structurally decouples the $\mathrm{V}_{2} \mathrm{O}_{3}$ layer from the $\mathrm{Al}_{2} \mathrm{O}_{3}$ substrate.

Fig. 5 shows the resistivity hysteresis curves for $\mathrm{V}_{2} \mathrm{O}_{3}$ grown on $\mathrm{Cr}_{2} \mathrm{O}_{3} / \mathrm{Al}_{2} \mathrm{O}_{3}$. We note that $\mathrm{Cr}_{2} \mathrm{O}_{3}$ is an insulator with a band gap of $3.4 \mathrm{eV}$ and resistivity measurements on independently grown films have shown very high resistivity values. Hence, the features seen in Fig. 5 are entirely to be attributed to those of the thin $\mathrm{V}_{2} \mathrm{O}_{3}$ layers. The $57 \mathrm{~nm}$ layers on $\mathrm{Al}_{2} \mathrm{O}_{3}$ and $56 \mathrm{~nm}$ layer on $\mathrm{Cr}_{2} \mathrm{O}_{3} / \mathrm{Al}_{2} \mathrm{O}_{3}$ are comparable in terms of hysteresis, transition width and RR $\left(8.1 \times 10^{4}\right)$, but the latter has a higher $\mathrm{T}_{\mathrm{MIT}}$ around $151 \mathrm{~K}$ which is closer to the bulk value. The layers on $\mathrm{Cr}_{2} \mathrm{O}_{3}$ all exhibit a metallic slope before the MIT with resistivity values between $8.7 \times 10^{-4}$ and $1.3 \times 10^{-3} \Omega \mathrm{cm}$ at $300 \mathrm{~K}$. An asymmetry is again sometimes observed between resistances along different directions for the thin layers. In contrast with the thin layers of $\mathrm{V}_{2} \mathrm{O}_{3}$ deposited directly on $\mathrm{Al}_{2} \mathrm{O}_{3}$, a MIT is evident in all layers from the sharp increase in resistivity below $150 \mathrm{~K}$ and the reduced slope in the insulating region compared to the transition region (notably on the heating curve). From the hysteresis, we find a RR of two orders of magnitude in the $3.5 \mathrm{~nm}$ layer.

Coherent strain can have a two-fold effect on the transport properties. On the one hand, the structural transition associated with the MIT can be attenuated due to structural clamping to the substrate. On the other hand, the large strain can dramatically influence the electronic structure. A strain state with respect to bulk $\mathrm{V}_{2} \mathrm{O}_{3}$ of $-4.22(-4.01) \%$ and $+0.09(-0.17) \%$ for the in- and out-of-plane directions is extracted from the position of the coherent feature of the 4 (6) nm layer shown in Fig. 2. Attempts have been made to associate the strain state in thin $\mathrm{V}_{2} \mathrm{O}_{3}$ layers with the pressure scale on the bulk phase diagram, based on the a-axis compression $^{10}$ and the volume change. ${ }^{22}$ Both approaches predict a complete suppression of the MIT and metallic state at all temperatures in our coherent layers. In this context,

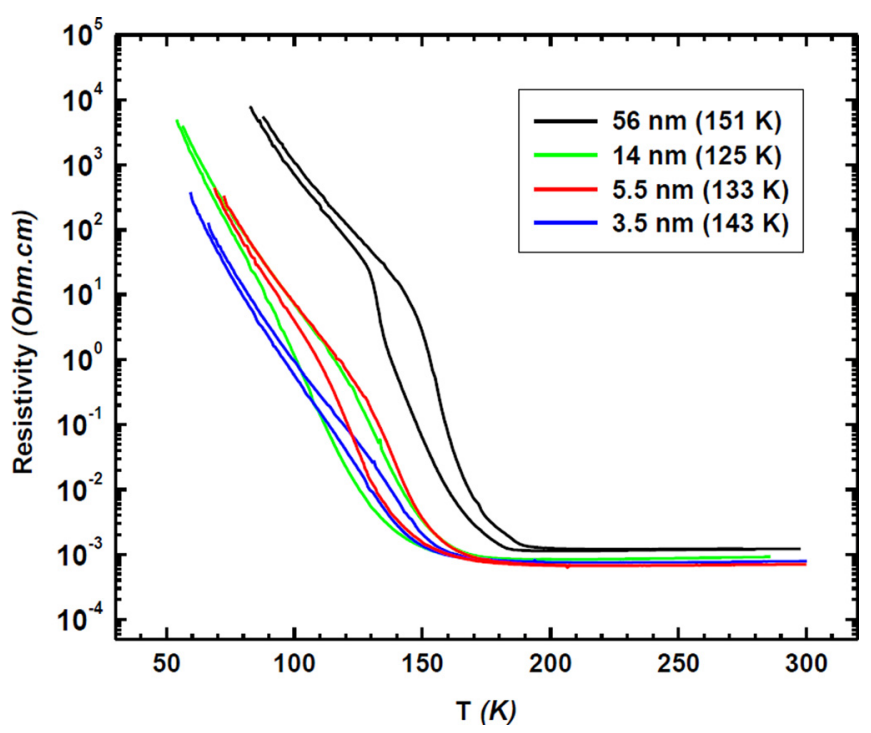

FIG. 5. Resistivity of $\mathrm{V}_{2} \mathrm{O}_{3}$ layers with different thickness deposited on $\mathrm{Cr}_{2} \mathrm{O}_{3} /(0001)-\mathrm{Al}_{2} \mathrm{O}_{3}$. $\mathrm{T}_{\text {MIT }}$ values are given in the legend. two scenarios can be considered to explain why there is nevertheless still an upturn in resistivity in the 6 and $4 \mathrm{~nm}$ layers. First of all, it is possible that the part of the layer, corresponding to the relaxed feature of the 6 and $4 \mathrm{~nm}$ samples, does in fact undergo the transition because (as opposed to the coherent part) it is not subject to such large in-plane compressive strain. If this relaxed part is associated with domains that exhibit a wide range of $\mathrm{T}_{\text {MIT }}$ values, this leads to a coexistence of insulating and metallic domains below the bulk $\mathrm{T}_{\mathrm{MIT}}$, where the transport is governed by percolation. On the other hand, the approaches of Refs. 10 and 22 somewhat neglect the role of the strain state along the c-axis, which could be important in determining the electronic state through a dependency of nearest-neighbor distances and trigonal field splitting (closely linked to the $\mathrm{MIT}^{23,24}$ ) on both a-axis and c-axis spacings. In other words, the volume change or a-axis length do not necessarily uniquely determine the state of the system. In this scenario, it is possible that the strain state is not solely responsible for the transport behavior, but clamping can in part cause the attenuation of the MIT.

We expect that the presence of a surface dead layer would, at least in principle, be apparent from an increased resistivity in the metallic phase for a decreasing layer thickness. Our results indicate however a decreased resistivity with decreasing thickness, suggesting that the dead layer should be significantly thinner than $4 \mathrm{~nm}$.

In conclusion, we have significantly changed the inplane strain state of ultrathin epitaxial $\mathrm{V}_{2} \mathrm{O}_{3}$ films by about $4.2 \%$ using buffer layers of $\mathrm{Cr}_{2} \mathrm{O}_{3}$ deposited on (0001) $-\mathrm{Al}_{2} \mathrm{O}_{3}$. Furthermore, we have observed a clear MIT in such $\mathrm{V}_{2} \mathrm{O}_{3}$ layers as thin as $3.5 \pm 1 \mathrm{~nm}$ grown on buffer layers of $\mathrm{Cr}_{2} \mathrm{O}_{3}$. This is in contrast with thin $\mathrm{V}_{2} \mathrm{O}_{3}$ layers directly grown on $\mathrm{Al}_{2} \mathrm{O}_{3}$. We explain these results by the different strain state of the $\mathrm{V}_{2} \mathrm{O}_{3}$ and/or the structural unclamping from the substrate resulting from the insertion of the $\mathrm{Cr}_{2} \mathrm{O}_{3}$ buffer layer. The demonstration of a MIT in ultrathin layers is of relevance for applications such as piezo-electric and field-effect transistors.

We acknowledge the support from agentschap voor Innovatie door Wetenschap en Technologie (IWT) and the Research Foundation Flanders (FWO). Discussions with Professor C. Van Haesendonck and Professors M. Van Bael, Bart Ydens, and Petar Bakalov are also acknowledged.

\footnotetext{
${ }^{1}$ M. Foex, C. R. Acad. Sci. III 223, 1126 (1946).

${ }^{2}$ D. B. McWhan, J. P. Remeika, T. M. Rice, W. F. Brinkman, J. P. Maita, and A. Menth, Phys. Rev. Lett. 27, 941 (1971).

${ }^{3}$ H. Schuler, S. Klimm, G. Weissmann, C. Renner, and S. Horn, Thin Solid Films 299, 119-124 (1997).

${ }^{4}$ S. A. Shivashankar and J. M. Honig, Phys. Rev. B 28, 5695-5701 (1983).

${ }^{5}$ M. Copel, M. A. Kuroda, M. S. Gordon, X.-H. Liu, S. S. Mahajan, G. J. Martyna, N. Moumen, C. Armstrong, S. M. Rossnagel, T. M. Shaw, P. M. Solomon, T. N. Theis, J. J. Yurkas, Y. Zhu, and D. M. Newns, Nano Lett. 13(10), 4650-4653 (2013).

${ }^{6}$ Y. Zhou and S. Ramanathan, Crit. Rev. Solid State Mater. Sci. 38(4), 286-317 (2013).

${ }^{7}$ G. Borghi, M. Fabrizio, and E. Tosatti, Phys. Rev. Lett. 102, 066806 (2009).

${ }^{8}$ S.-K. Mo, J. D. Denlinger, H.-D. Kim, J.-H. Park, J. W. Allen, A. Sekiyama, A. Yamasaki, K. Kadono, S. Suga, Y. Saitoh, T. Muro, P. Metcalf, G. Keller, K. Held, V. Eyert, V. I. Anisimov, and D. Vollhardt, Phys. Rev. Lett. 90, 186403 (2003).
} 
${ }^{9}$ F. Rodolakis, B. Mansart, E. Papalazarou, S. Gorovikov, P. Vilmercati, L. Petaccia, A. Goldoni, J. P. Rueff, S. Lupi, P. Metcalf, and M. Marsi, Phys. Rev. Lett. 102, 066805 (2009).

${ }^{10}$ S. Yonezawa, Y. Muraoka, Y. Ueda, and Z. Hiroi, Solid State Commun. 129, 245-248 (2004).

${ }^{11}$ C. Grygiel, A. Pautrat, W. C. Sheets, W. Prellier, B. Mercey, and L. Méchin, J. Phys.: Condens. Matter 20, 472205 (2008).

${ }^{12}$ Q. Luo, Q. Guo, and E. G. Wang, Appl. Phys. Lett. 84, 2337 (2004).

${ }^{13}$ L. Dillemans, R. R. Lieten, M. Menghini, T. Smets, J. W. Seo, and J. P. Locquet, Thin Solid Films 520, 4730 (2012).

${ }^{14}$ D. B. McWhan and J. P. Remeika, Phys. Rev. B 2, 3734-3750 (1970).

${ }^{15}$ J.-P. Locquet, J. Perret, J. Fompeyrine, E. Mächler, J. W. Seo, and G. Van Tendeloo, Nature 394, 453-456 (1998).

${ }^{16}$ J. Brockman, M. G. Samant, K. P. Roche, and S. S. P. Parkin, Appl. Phys. Lett. 101, 051606 (2012).

${ }^{17}$ B. S. Allimi, M. Aindow, and S. P. Alpay, Appl. Phys. Lett. 93, 112109 (2008).
${ }^{18}$ S. Autier-Laurent, B. Mercey, D. Chippaux, P. Limelette, and Ch. Simon, Phys. Rev. B 74, 195109 (2006).

${ }^{19}$ I. Yamaguchi, T. Manabe, T. Kumagai, W. Kondo, and S. Mizuta, Thin Solid Films 366, 294-301 (2000).

${ }^{20}$ C. Grygiel, Ch. Simon, B. Mercey, W. Prellier, R. Frésard, and P. Limelette, Appl. Phys. Lett. 91, 262103 (2007).

${ }^{21}$ H. Schuler, G. Weissmann, C. Renner, S. Six, S. Klimm, F. Simmet, and S. Horn, Symposium G - Epitaxial Oxide Thin Films II, edited by D. K. Fork, T. Shiosaki, J. S. Speck, and R. W. Wolf (Mater. Res. Soc. Symp. Proc., 1996), Vol. 401, pp. 61-66.

${ }^{22}$ B. S. Allimi, S. P. Alpay, C. K. Xie, B. O. Wells, J. I. Budnick, and D. M. Pease, Appl. Phys. Lett. 92, 202105 (2008).

${ }^{23}$ M. S. Laad, L. Craco, and E. Müller-Hartmann, Phys. Rev. Lett. 91, 156402 (2003).

${ }^{24}$ A. I. Poteryaev, J. M. Tomczak, S. Biermann, A. Georges, A. I. Lichtenstein, A. N. Rubtsov, T. Saha-Dasgupta, and O. K. Andersen, Phys. Rev. B 76, 085127 (2007). 